GRASAS Y ACEITES 69 (3)

July-September 2018, e262

ISSN-L: 0017-3495

https://doi.org/10.3989/gya.1112172

\title{
Isolation of the unsaponifiable matter (squalene, phytosterols, tocopherols, $\gamma$-oryzanol and fatty alcohols) from a fatty acid distillate of rice bran oil
}

\author{
S. Sahu ${ }^{\mathrm{a}}$, M. Ghosh ${ }^{\mathrm{a}, \bigotimes}$ and D.K. Bhattacharyya ${ }^{\mathrm{a}}$ \\ ${ }^{a}$ School of Community Science and Technology, Indian Institute of Engineering Science and Technology, Shibpur \\ ${ }^{\square}$ Corresponding author: g_minakshi2000@yahoo.com
}

Submitted: 20 November 2017; Accepted: 06 April 2018

\begin{abstract}
SUMMARY: Rice bran oil is characterized by its unique composition of unsaponifiable matter such as oryzanol, squalene, sterols, tocopherols and fatty alcohols. Rice bran oil fatty acid distillate (RBOFAD) is an important by-product of physical refining plants. In the present study, an appropriate fractionation methodology is proposed for isolating the unsaponifiable matter into two fractions, squalene, phytosterols and fatty alcohols as fraction 1; tocopherols and $\gamma$ - oryzanol as fraction 2. The two fractions together constitute the total unsaponifiable matter in the RBOFAD. The individual unsaponifiable matter components ( $\gamma$-oryzanol $1.78 \mathrm{~g} / 100 \mathrm{~g}$, squalene $209.63 \mathrm{mg} / 100 \mathrm{~g}$, tocopherol $2.45 \mathrm{mg} / 100 \mathrm{~g}$, total phytosterols $3.79 \mathrm{~g} / 100 \mathrm{~g}$ and fatty alcohols $94.23 \mathrm{~g} / 100 \mathrm{~g}$ ) were isolated from RBOFAD by combining a chemical esterification process and liquid-liquid extraction process with $95 \%$ ethanol which extracted tocopherol, $\gamma$-oryzanol, sterols, squalene, FFA, monoglycerides; later with hexane extraction of the alkaline phase to remove squalene, sterols and fatty alcohols. The alkaline salts of tocopherols and $\gamma$-oryzanol are decomposed by the acidification and extraction of the unsaponifiable matter with n-hexane.
\end{abstract}

KEYWORDS: Esterification; Fatty Acid Distillate; Rice Bran Oil; Unsaponifiable matter

RESUMEN: Aislamiento del insaponificable (escualeno, fitosteroles, tocoferoles, $\gamma$-orizanol y alcoholes grasos) de destilados grasos del aceite de salvado de arroz. El aceite de salvado de arroz se caracteriza por su composición única en materia insaponificable como orizanol, escualeno, esteroles, tocoferoles y alcoholes grasos. El destilado graso de los aceites de salvado de arroz (RBOFAD) es un subproducto importante en las plantas de refinación física. En el presente estudio se presenta una metodología de fraccionamiento apropiada para aislar la materia insaponificable en dos fracciones, principalmente escualeno, fitosteroles y alcoholes grasos como fracción 1; tocoferoles y $\gamma$-orizanol como fracción 2. Las dos fracciones juntas constituyen la materia insaponificable en el RBOFAD cuyo fraccionamiento ha sido desarrollado y adoptado. Los componentes individuales insaponificables ( $\gamma$-orizanol 1,78g/ 100g, escualeno 209,63 mg/100g, tocoferoles 2,45mg/100g, fitoesteroles totales 3,79g/100g y alcoholes grasos $94,23 \mathrm{~g} / 100 \mathrm{~g}$ ) se aislaron de RBOFAD al combinar los procesos de esterificación química y extracción líquido-líquido con etanol al 95\% que extrajo tocoferoles, $\gamma$-orizanol, esteroles, escualeno, FFA, monoglicéridos. A continuación, mediante extracción con hexano de fase alcalina se aisla escualeno, esteroles y alcoholes grasos. Las sales alcalinas de tocoferoles y $\gamma$-orizanol se descompone por acidificación y se extrae de materia insaponificable con n-hexano.

PALABRAS CLAVE: Aceite de salvado de arroz; Destilado de ácido graso; Esterificación; Insaponificable

ORCID ID: Sahu S https://orcid.org/0000-0002-9446-9584, Ghosh M https://orcid.org/0000-0002-7868-0785, Bhattacharyya DK https://orcid.org/0000-0001-7145-3654

Citation/Cómo citar este artículo: Sahu S, Ghosh M, Bhattacharyya DK. 2018. Isolation of unsaponifiable matter (squalene, phytosterols, tocopherols, $\gamma$-oryzanol and fatty alcohols) from fatty acid distillate of rice bran oil. Grasas Aceites 69 (3), e262. https://doi.org/10.3989/gya.1112172

Copyright: (C2018 CSIC. This is an open-access article distributed under the terms of the Creative Commons Attribution 4.0 International (CC BY 4.0) License. 


\section{INTRODUCTION}

Rice bran oil is a good source of natural antioxidants such as tocopherol, $\gamma$-oryzanol, squalene and phytosterol, which can be used as free radical scavengers. These antioxidants provide hydrogen to neutrilize free radicals. Rice bran oil is a valuable functional food and it prevents various health diseases such as cardiovascular disease, cancer, skin disease etc. Rice bran oil improves the immune and nervous systems in the human body (Nayik et al., 2015). Rice bran oil contains considerably high amounts $(4 \%)$ of unsaponifiable matter such as phytosterols, fatty alcohols, tocopherols and $\gamma$-oryzanol, compared to other vegetable oils (Wilson et al., 2007). The antioxidants in rice bran oil are more effective for lowering total serum cholesterol and low density lipoprotein in cholesterol in humans and animals. $\gamma$-oryzanol is known to be a fraction containing ferulate (4-hydroxy 3-methoxy cinnamic acid) esters of phytosterol and triterpene alcohol (Arab and Alemzadeh, 2011). The three main components of $\gamma$-oryzanol from rice bran oil are Cycloartenyl Ferulate, 24-methylenecycloartanyl Ferulate and Campesteryl Ferulate (Sohail et al., 2017). $\gamma$-oryzanol has been used as a potential additive in many food sectors, cosmetics and pharmaceutical industries (Lloyd, Siebenmorgen and Beers, 2000) . Therefore, $\gamma$-oryzanol is important for recovery by extraction from a fatty acid distillate of rice bran oil.

Tocopherols and tocotrienols $(\alpha, \beta, \gamma$ and $\delta)$ are contained in rice bran oil and are also important phytochemicals with antioxidant activities and they have potential health benefits (Chen and Bergman, 2005). Generally, tocopherols are present in rice bran oil, corn oil and soya bean oil, palm oil etc. Tina A. Gomes reported the isolation of a tocol-rich fractionation from a deodorized distillate of rice bran oil (Gomes et al., 2015).

Squalene, a trace component, is generally found in marine animal oils and has been studied for its preventive effect from many conditions such as cancer and cardiovascular diseases (Smith, 2000; Escrich, Solanas and Moral, 2014). Recently, squalene has gained attention as a nutrient in various food sectors (Bhilwade et al., 2010). Shark liver oil is known to be a rich source of squalene but, since recently, it is no longer utilized on humanitarian grounds. Therefore, attention has shifted towards appling the squalene from plant origin in various medicines, cosmetics and functional foods.

The main phytosterols of rice bran oil are campesterol, $\beta$-sitosterol, stigmasterol and isofucosterol and are contained in rice bran oil at 20\%,50\%,15\% and 5\%, respectively (Yamamoto and Har, 2012). It is known that phytosterols from plant origin inhibit the absorption of cholesterol in the small intestine of the human body which results in the cholesterolreducing activity of phytosterols (Malinowski and Gehret, 2010; Nijjar et al., 2010; Gupta et al., 2011). Phytosterol constituents are useful substances for the application of functional foods for health use.

Fatty alcohols are mainly derived from vegetable oils and serve as raw materials for making oleogel, which is recently gaining importance in bakery applications, various household products and surfactants (Troni et al., 2013). Crude rice bran oil invariably contains wax principally in the form of wax esters. The wax esters are removed by crystallization at low temperature before the oil is de-acidified by a physical refining process. It could be that the wax esters remaining in the oil have been hydrolyzed to give fatty alcohols, which are removed by steam distillation along with fatty acids in the fatty acid distillate. In addition, the esterified oil contains fatty alcohols even after the esterification step.

Rice bran oil fatty acid distillate (RBOFAD) is a by-product of the physical refining of rice bran oil and is a valuable source of $\gamma$-oryzanol, tocopherol, total phytosterol, squalene and fatty alcohol.

Approximately 6 tonnes RBOFAD are produced for every 100 tonnes of crude rice bran oil. Esterification is a process for the removal of high free fatty acids (FFA) in vegetable oil. The re-esterification of fatty acids with glycerol to neutral glycerides has been reported in the literature. A study of the esterification (chemical) of high FFA (15-30\%) RBO was reported using metal salts and an acid catalyst (Bhattacharyya and Bhattacharyya, 1987; Kombe et al., 2013). Bhattacharyya and Bhattacharyya presented a FFA content reduction from $30 \%$ to $2 \%$ using acid catalyst, and after further alkali refining, bleaching and deodorization, obtained an acceptable oil color. This chemical esterification process removes high FFA from the oil sample with odoriferous compounds at a high temperature under vacuum. The fundamental objective was that the esterification involved the conversion of high FFA into neutral glycerides by a reaction with free hydroxyl groups remaining in the oil or with the added hydroxyl group from glycerol at a high temperature under high vacuum with or without catalyst (Bhosle and Subramanian, 2005). So, the main advantage of the chemical esterification process for the de-acidification of fatty acid distillate from rice bran oil with high FFA content was to increase the contents of neutral glycerides such as monoglyceride (MG), diglyceride (DG) and triglyceride (TG).

The primary objective of the present investigation is to develop appropriate process technology for the isolation of $\gamma$-oryzanol, phytosterol, tocopherol, 
squalene and fatty alcohols from rice bran oil fatty acid distillates for food application as valuable antioxidants or micronutrients.

\section{MATERIALS AND METHODS}

\subsection{Materials}

The fatty acid distillate of rice bran oil was supplied by Sethia Oils Ltd. (Burdwan, West Bengal, India). All samples were stored in amber bottles at $4-5{ }^{\circ} \mathrm{C}$ until analysis.

\subsection{Quality assessment of fatty acid distillate from rice bran oil}

The quality of the fatty acid distillate from rice bran oil was measured by its chemical properties in terms of acid value (AOAC 969.17), saponification value (AOAC 920.160), unsaponifiable matter (AOAC 972.28) and peroxide value (AOAC 965.33) and followed standard AOAC methods of analysis (Qu et al., 2017).

\subsection{Esterification process for making neutral glycerides from FAD}

The fatty acid distillate of rice bran oil $(100 \mathrm{~g})$ was kept in a round-bottom flask $(250 \mathrm{~mL}, \mathrm{~B}-24$ joint $)$. A pre-determined amount (theoretical amount) of glycerol was added to the RBOFAD and it was slowly heated to $160^{\circ} \mathrm{C}, 180^{\circ} \mathrm{C}, 200^{\circ} \mathrm{C}, 220^{\circ} \mathrm{C}$ and $250^{\circ} \mathrm{C}$ in a $30 \mathrm{~mm} \mathrm{Hg}$ vacuum and stirred with a magnetic bar $(2.54 \mathrm{~cm})$ without any catalyst. Samples were drawn at 4-hour intervals to measure free fatty acid contents until no further reduction in free fatty acid occurred (De and Bhattacharyya, 1999).

\subsection{Quality assessment of esterified oils}

The quality of the esterified oil from the fatty acid distillate was assessed according to its chemical properties in terms of acid value (AOAC 969.17), peroxide value (AOAC 965.33), saponification value (AOAC 920.160) and unsaponifiable matter (AOAC 972.28) and followed standard AOAC methods (Qu et al., 2017).

\subsection{Color parameters}

The color of the rice bran fatty acid distillate and the esterified oil of RBOFAD were determined before and after the esterification reaction at a high temperature and under vacuum by Konica Minolta Color Reader CR 10 (Japan). The color was measured for three different points of each sample such as "L" (Lightness), "a+" (Redness) and "b+" (Yellowness) (Domínguez et al., 2016).

\subsection{Thin-layer chromatography of fatty acid distillate and esterified oil of rice bran oil}

The monoglyceride (MG), diglyceride (DG) and triglyceride (TG) of the fatty acid distillate from rice bran oil and the esterified oil of the fatty acid distillate were measured by Thin-layer chromatography (TLC) according to the authors (De and Bhattacharyya, 1999). TLC grade silica gel $\mathrm{G}(20 \mathrm{~g})$ was applied on a $20 / 20 \mathrm{~cm}$ glass plate using $40 \mathrm{~mL}$ distilled water and a TLC applicator. This silica plate was activated at $100{ }^{\circ} \mathrm{C}$ in a hot air oven for $60 \mathrm{~min}$. Then, the oil sample $(0.01 \mathrm{~g})$ was spotted onto each activated silica plate and then this plate was dipped in $100 \mathrm{~mL}$ solvent mixture (n-hexane/diethyl ether; 80:20, v/v). MG, DG and TG spots were visualized with iodine and then identified by $\mathrm{Rf}$ values (The ratio of the distance travelled by the individual compounds divided by the distance travelled by the solvent). Each spot was scooped up from the silica plates and MG, DG and TG were extracted using a methanol and chloroform mixture.

The quantification of MG, DG and TG were estimated by the evaporation of solvent under vacuum $\left(30 \mathrm{~mm} \mathrm{Hg}\right.$ ) at $90^{\circ} \mathrm{C}$ and the results were assessed on a weight basis of oil sample. Although very tentative, this method is often adopted in order to get a relative distribution pattern of the proportions of the various neutral glycerides in the fatty acid distillate (FAD) and esterified FAD of rice bran oil. In fact, it is a very rapid but relatively less accurate method for ascertaining the contents of various acyl glycerols.

\subsection{Fatty acids composition of fatty acid distillates and neutral glycerides}

The fatty acid methyl esters (FAME) of FAD and neutral glyceride of FAD were analyzed by Gas Chromatography (GC) with a Flame Ionization Detector (FID) system and EB-5 capillary column to compare them with a known standard fatty acid mixture according to the research by (Domínguez et al., 2016). The GC injector and detector temperatures were maintained at $250{ }^{\circ} \mathrm{C}$ and $290{ }^{\circ} \mathrm{C}$, respectively. The injector volume of the oil sample was $1 \mu \mathrm{L}$ and the carrier gas was nitrogen at a flow rate of $45 \mathrm{~mL} / \mathrm{min}$; the split ratio was 1:50. The retention time of each fatty acid methyl ester was compared against standard fatty acid methyl esters for the identification of FAME composition.

\subsection{Isolation of the unsaponifiable matter from the esterified rice bran oil fatty acid distillates}

After the esterification reaction, the molecular weight of the fatty acid distillate increased significantly due to its conversion into neutral glycerides and as a result the proportions of the unsaponifiable constituents decreased as is evident from the 
proportion of the individual components. Further, the extraction of the unsaponifiable matter with 95\% alcohol solubilised the individual unsaponifiable matter components as well as the FFA present in the esterified product along with the MGs and DGs. Subsequently, the alcohol soluble fraction was saponified to separate the oryzanol and tocopherol as their potassium salts in the aqeous phase while the squalene, sterols and fatty alcohols remained in the upper organic solvent (hexane) phase.

Accordingly, the distribution (Wt \%) of the unsaponifiable matter constituents varied in the different products. The unsaponifiable matter was isolated from the esterified oil (FFA Wt \% 1.97 as oleic acid) through liquid-liquid extraction with $95 \%$ alcohol, as shown in Figure 1. Each value given below is the average of three determinations, mean $\pm \mathrm{SD}$.

\subsection{Thin-layer chromatography (TLC) of upper layer and lower layer}

The presence of squalene, phytosterols, fatty alcohol, tocopherols and $\gamma$-oryzanol in the esterified oil was studied by Thin-layer Chromatography (TLC)
(Rani et al., 2015). TLC grade silica gel G (20 g) was applied onto a $20 \times 20 \mathrm{~cm}$ glass plate using $40 \mathrm{~mL}$ distilled water and a TLC applicator. The silica plates were activated in a hot air oven at $100{ }^{\circ} \mathrm{C}$ for $60 \mathrm{~min}$. $0.01 \mathrm{~g}$ of each sample (accurately weighed) was spotted onto each plate and these plates were dipped in $100 \mathrm{~mL}$ of a n-hexane/diethyl ether (80:20, v/v) mixture. The various spots were visualized by iodine absorption in an iodine chamber and identified by $\mathrm{Rf}$ values (The ratio of the distance travelled by the individual compounds divided by the distance travelled by the solvent) as shown in Figure 2 .

\subsection{0. $\gamma$-oryzanol content determination}

The $\gamma$-oryzanol content (\%) of the oil was determined from the spectrophotometer absorption measurements at the wavelength of maximum absorption near $314 \mathrm{~nm}$ (Khatoon and Gopalakrishna, 2004). Approximately $0.01 \mathrm{~g}$ of the sample was weighed accurately into a $10 \mathrm{~mL}$ volumetric flask which was then made up to mark with n-hexane. The cuvette was filled with the obtained solution, and the extinction coefficient was measured at the wavelength of

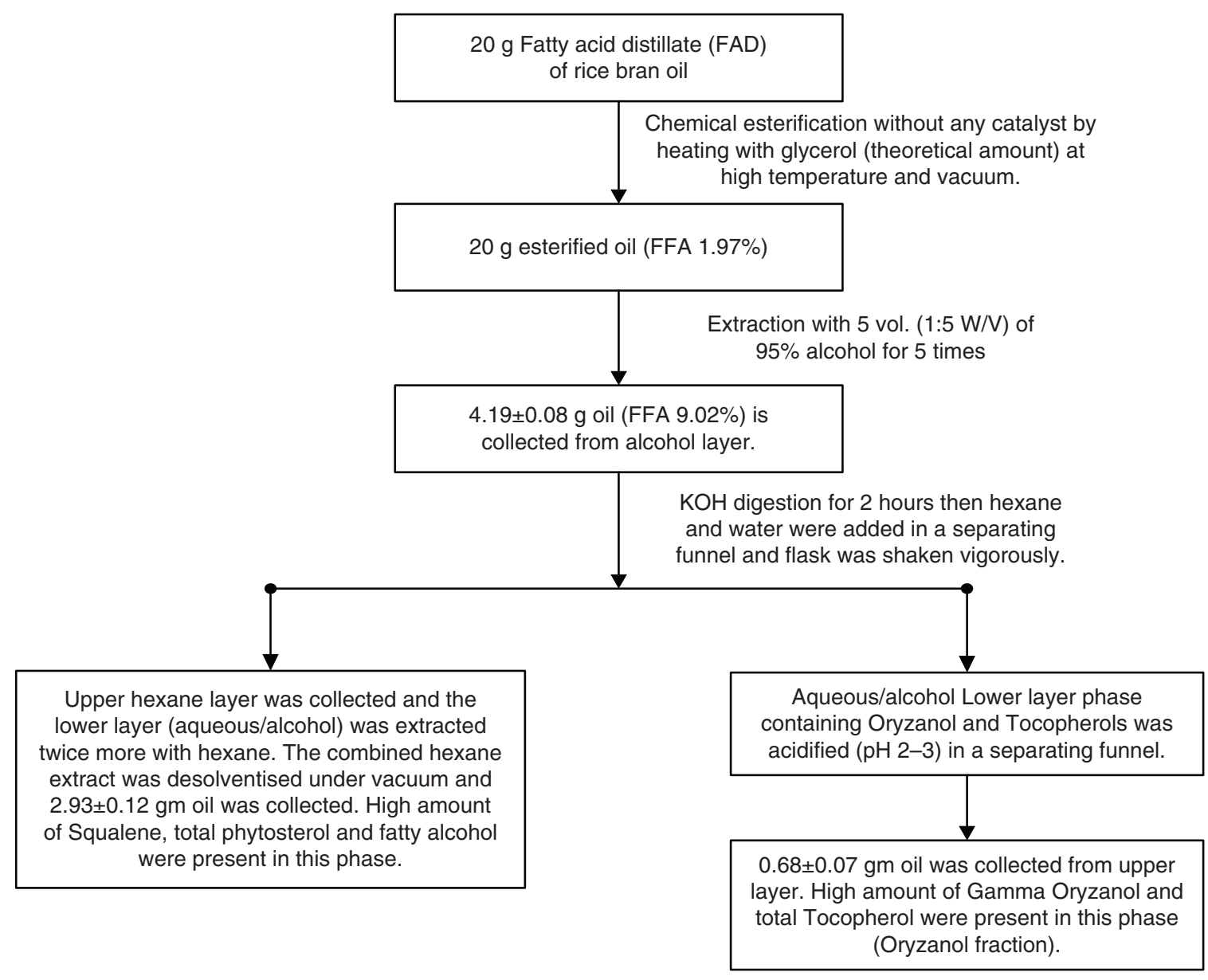

FIGURE 1. Extraction of the unsaponifiable matter components from the esterified oil of the fatty acid distillate of RBO. 

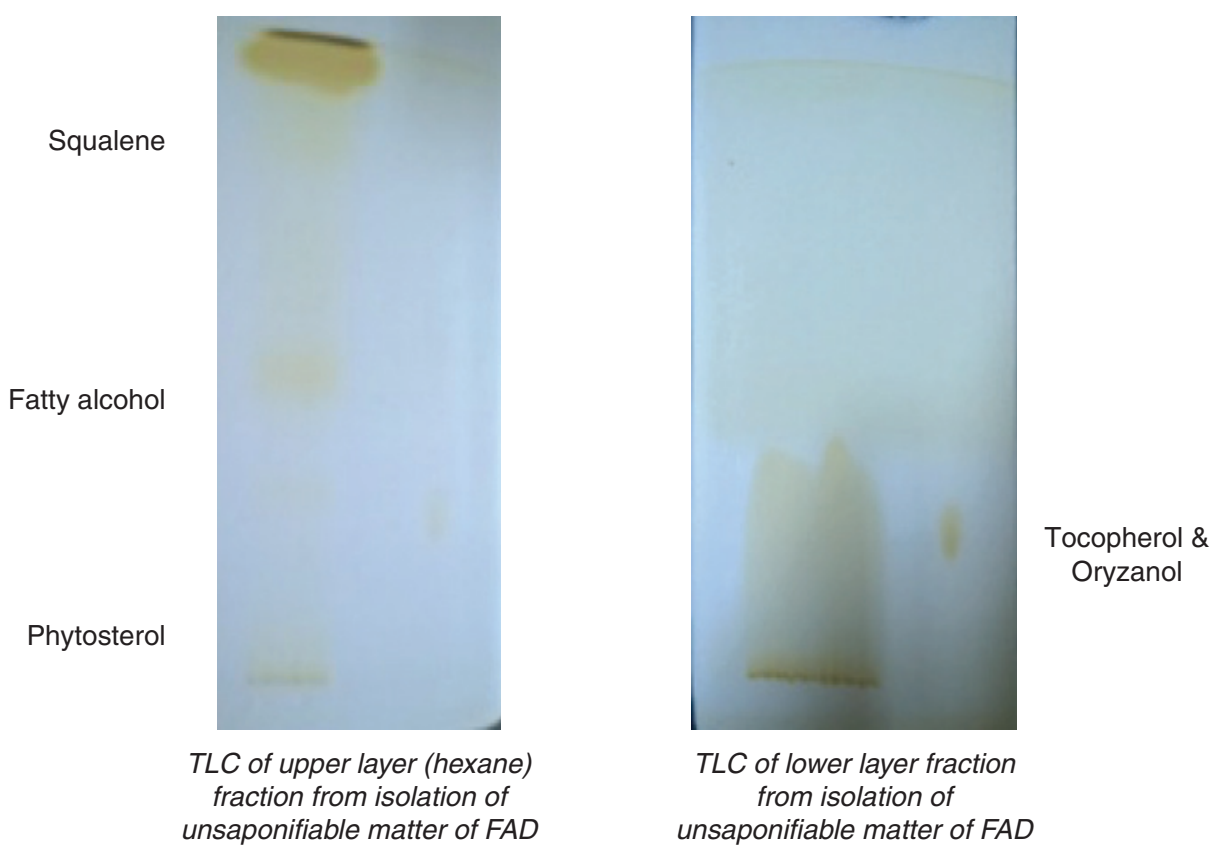

Figure 2. Thin-layer chromatography (TLC) of the upper and lower layers.

maximum absorption near $314 \mathrm{~nm}$, using the same solvent as a reference. The $\gamma$-oryzanol percentage was calculated according to the formula:

$\begin{aligned} & \gamma-\text { oryzanol } \\ & \text { content },(\mathrm{g}) \%\end{aligned}=\frac{\text { OD value of hexane solution }}{\text { Weight of oil }(\mathrm{g}) \times 10} \times \frac{100}{358.9}$

Specific extinction $\mathrm{E} 1 \% 1 \mathrm{~cm}=358.9$

\subsection{Total tocopherol content determination}

The total tocopherol analysis was done using the HPLC system (Agilent Technologies) equipped with an Agilent Zorbax RX - SIL (5 $\mu \mathrm{m}, 4.6 \times 250 \mathrm{~mm})$ column and mobile phase of $3.85 \%$ Tetrahydrofuran in n-Heptane and Fluorescence detection (excitation $-295 \mathrm{~nm}$ and emission-330 nm) was used for analysis (Uluata, Altuntaş and Özçelik, 2016). The identification of tocopherols was done by comparing the retention times of internal standards and the quantitative value of the tocopherols was measured by comparing the peak areas with the internal standard.

\subsection{Determination of total phytosterol and fatty alcohol contents}

The unsaponifiable matter after isolation was analyzed by Agilent Gas Chromatgraphy (GC) with a capillary column and Flame Ionization Detector (FID) at $350{ }^{\circ} \mathrm{C}$ for the determination of phytosterol and fatty alcohol (Delange et al., 2013; Uluata, Altuntaş and Özçelik, 2016). Initially, the oven temperature of $\mathrm{GC}$ was $100{ }^{\circ} \mathrm{C}$ and injection temperature was held at $280{ }^{\circ} \mathrm{C}$ for $45 \mathrm{~min}$. Then the temperature was gradually increased to $300{ }^{\circ} \mathrm{C}$ (at a rate of $5^{\circ} \mathrm{C} / \mathrm{min}$ ), and held for $15 \mathrm{~min}$. The split ratio was 10:1 and the carrier gas flow was $0.5 \mathrm{~mL} \mathrm{He} /$ min. The total Phytosterol and fatty alcohol contents were identified by comparing the retention times of phytosterols and fatty alcohol in the samples with those of internal standards.

\subsection{Squalene content determination}

After the isolation of unsaponifiable matter, the squalene content was analyzed by an Agilent Gas Chromatography (GC) system for the determination of squalene with a capillary column and a Flame Ionization Detector (FID) at $350{ }^{\circ} \mathrm{C}$ (Uluata, Altuntaş and Özçelik, 2016). Initially, the oven temperature of $\mathrm{GC}$ was set at $100{ }^{\circ} \mathrm{C}$ and the injection temperature was held at $280^{\circ} \mathrm{C}$ for $45 \mathrm{~min}$. Then the temperature was gradually increased to $300{ }^{\circ} \mathrm{C}$ (at a rate of $5^{\circ} \mathrm{C} / \mathrm{min}$ ) and held for $15 \mathrm{~min}$. The split ratio was $10: 1$ with a carrier gas flow of $0.5 \mathrm{~mL} \mathrm{He} / \mathrm{min}$. The Squalene content was identified by comparing the retention time of squalene in the samples with the internal standards for quantification.

\section{RESULTS AND DISCUSSION}

\subsection{Conversion of fatty acid distillate into neutral glyceride}

The fatty acid distillate was converted into neutral glyceride with a theoretical amount of glycerol at high temperatures $\left(160{ }^{\circ} \mathrm{C}-250{ }^{\circ} \mathrm{C}\right)$ and $30 \mathrm{~mm}$ of $\mathrm{Hg}$ vacuum. In this esterification process, the free fatty 
acid of fatty acid distillate (FFA $81.83 \%$ at room temperatura, $30{ }^{\circ} \mathrm{C}$ ) was gradually decreased (FFA $81.83 \%$ to $1.97 \%$ as oleic acid) with the rise in temperature from $160{ }^{\circ} \mathrm{C}$ to $180^{\circ} \mathrm{C}$, as shown in Figure 3 .

\subsection{Chemical properties of original fatty acid distillate from RBO and of the neutral glyceride of FAD}

Acid value, saponification value, peroxide value and unsaponifiable matter are important quality factors for vegetable oils. The chemical properties of the FAD from rice bran oil and the esterified oil of FAD are shown in Table 1. The acid value, unsaponifiable matter and peroxide value of FAD from $\mathrm{RBO}$ were greater than the neutral glyceride of FAD from rice bran oil. At high temperatures, peroxides become decomposed and therefore, the peroxide value of esterified oil is lower than that of the rice bran fatty acid distillate and the acid value decreases with a simultaneous increase in the proportion of neutral glycerides, predominantly TAG, followed by DAG and MAG.

\subsection{Color parameters}

Table 2 shows the color of the fatty acid distillate and esterified FAD from rice bran oil as determined by the Konica Minolta Color Reader CR10. Due to some degradation reactions, the color of esterified oil showed more light intensity, which means a deeper color than the original fatty acid distillate of RBO.

\subsection{Fatty acid compositions of FAD from RBO and neutral glyceride of FAD}

The fatty acid compositions of FAD from RBO and the neutral glyceride of FAD were analyzed by Gas Chromatography using a Flame Ionization

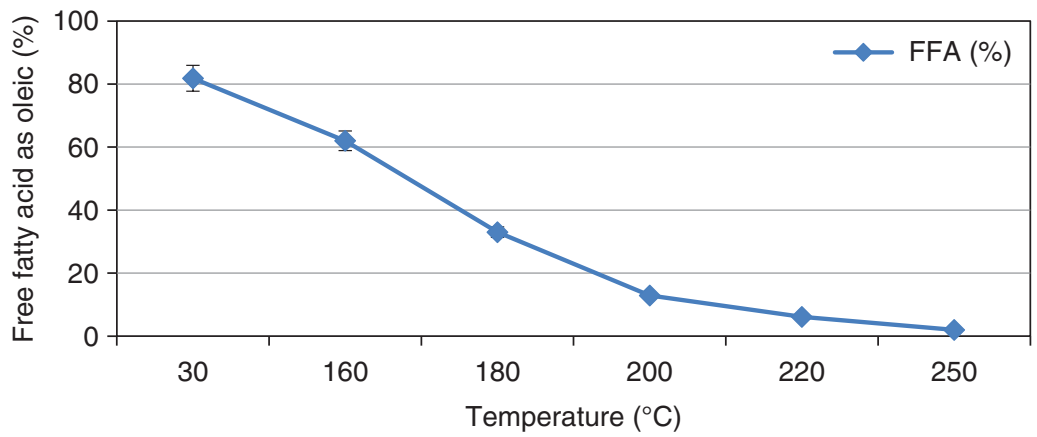

FIGURE 3. Conversion of fatty acid distillate into neutral glyceride with a theoretical amount of glycerol.

TABLE 1. Analytical characteristics of FAD from rice bran oil and neutral glyceride of FAD from RBO

\begin{tabular}{lcc}
\hline Analytical characteristics & $\begin{array}{c}\text { Original Fatty acid } \\
\text { distillate (FAD) }\end{array}$ & $\begin{array}{c}\text { Esterified Fatty } \\
\text { acid distillate }\end{array}$ \\
\hline Acid value (mg of KOH per g of oil) & $163.66 \pm 0.57^{\mathrm{a}}$ & $3.94 \pm 0.56^{\mathrm{a}}$ \\
Free fatty acid as oleic (Wt. \%) & $81.83 \pm 0.288^{\mathrm{a}}$ & $1.97 \pm 0.28^{\mathrm{a}}$ \\
Saponification value (mg of KOH per gm of oil) & $181.38 \pm 5.66^{\mathrm{b}}$ & $187.46 \pm 8.56^{\mathrm{b}}$ \\
Peroxide value (meq of O2 per kg of oil) & $8.33 \pm 2.88^{\mathrm{a}}$ & $1.94 \pm 0.10^{\mathrm{a}}$ \\
Unsaponifiable matter (Wt. \%) & $11.30 \pm 0.26^{\mathrm{a}}$ & $10.42 \pm 0.025^{\mathrm{a}}$ \\
Triglyceride (\% W/W) & $0.52 \pm 0.02^{\mathrm{a}}$ & $59.34 \pm 0.21^{\mathrm{a}}$ \\
Diglyceride (\%W/W) & $2.02 \pm 0.06^{\mathrm{a}}$ & $21.15 \pm 0.30^{\mathrm{a}}$ \\
Monoglyceride (\%W/W) & $3.99 \pm 0.02^{\mathrm{a}}$ & $7.21 \pm 0.25^{\mathrm{a}}$ \\
\hline
\end{tabular}

Each value is an average of three determinations, mean $\pm \mathrm{SD}$. The ' $\mathrm{a}$ ' and ' $\mathrm{b}$ ' indicate $\mathrm{P}<0.05$ differences, ' $\mathrm{a}$ ' $=$ at 0.05 level, the population means are significantly different, ' $\mathrm{b}$ ' $=$ at 0.05 level, the population means are not significantly different

TABLE 2. Color parameters of the fatty acid distillate of RBO and esterified oil of the fatty acid distillate from RBO

\begin{tabular}{lcrc}
\hline Samples & L (Lightness) & $\mathbf{a}^{+}$(Redness) & $\mathbf{b}^{+}$(Yellowness) \\
\hline Fatty acid distillate & $51.73 \pm 0.07$ & $0.65 \pm 0.05$ & $17.86 \pm 0.10$ \\
Esterified oil & $44.04 \pm 0.05$ & $10.60 \pm 0.02$ & $10.85 \pm 0.07$ \\
\hline
\end{tabular}

Each value is an average of three determinations, mean \pm SD. 
Detector (FID) (table 2). There are five fatty acids, namely, myristic acid (C14:0), palmitic acid (C16:0), stearic acid (C18:0), oleic acid (C18:1n9c), and linoleic acid (C18:2n6c) in these oils. Only slight differences in fatty acid compositions were observed between the FAD of RBO and neutral glyceride of FAD from RBO (Table 3).

\section{5. $\gamma$-oryzanol content}

The isolation of $\gamma$-oryzanol from the FAD of RBO depends on the extraction and processing conditions. The results from the $\gamma$-oryzanol estimation revealed that the $\gamma$-oryzanol content of the oryzanol-tocopherol fraction (fraction 2) was higher $(5.10 \mathrm{~g} / 100 \mathrm{~g})$ than the FAD of rice bran oil $(0.38 \mathrm{~g} / 100 \mathrm{~g})$ (Table 4 and Figures 1 and 2). $\gamma$-Oryzanol is a natural antioxidant which can be used as a food nutrient in various food sectors. Therefore, $\gamma$-oryzanol is an essential extraction from the fatty acid distillate of rice bran oil.

\subsection{Total tocopherol content}

Tocopherols are valuable antioxidants (lipid soluble) present in rice bran oil. The extraction of total tocopherols from the FAD of RBO depends on the processing conditions and the results from the total tocopherol estimation using a HPLC (Agilent Technologies) revealed that the total tocopherol

TABLE 3. Fatty acid compositions of the FAD from rice bran oil and the neutral glyceride of the FAD from RBO

\begin{tabular}{lcc}
\hline Fatty acids (Wt. \%) & $\begin{array}{c}\text { Rice bran oil } \\
\text { FAD (gm/100gm) }\end{array}$ & $\begin{array}{c}\text { Neutral glyeride } \\
\text { (gm/100gm) }\end{array}$ \\
\hline Myristic Acid (C14:0) & $0.28 \pm 0.01$ & $0.30 \pm 0.00$ \\
Palmitic Acid (C16:0) & $24.65 \pm 0.48$ & $27.50 \pm 0.03$ \\
Stearic Acid (C18:0) & $1.40 \pm 0.13$ & $1.65 \pm 0.04$ \\
Oleic Acid (C18:1n9c) & $41.46 \pm 0.10$ & $44.01 \pm 0.04$ \\
Linoleic Acid (C18:2n6c) & $30.40 \pm 0.04$ & $24.89 \pm 0.04$
\end{tabular}

Each value is an average of three determinations, mean \pm SD.

The t-test result is 0.50 using Microsoft excel t-test tool content of the oryzanol-tocopherol fraction (fraction 2) was higher $(2.10 \mathrm{~g} / 100 \mathrm{~g})$ than the FAD of rice bran oil $(1.26 \mathrm{mg} / 100 \mathrm{~g}$ ) (Table 4 and Figures 1 and 2 ). The Total tocopherol content of the FAD from $\mathrm{RBO}$ is a natural antioxidant which can be used as a food nutrient in various food sectors. Therefore, tocopherol is a vital extraction from the Fatty Acid Distillate of Rice Bran Oil.

\subsection{Total phytosterol content}

Phytosterols are the main components of the unsaponifiable matter from fats and oils. Therefore, the total phytosterol content is important for isolation from the FAD of RBO. Table 4 shows the higher percentage of total phytosterol content in the squalene-phytosterol fraction (fraction 1) from the FAD of rice bran oil. As shown in table 4, the total phytosterol content in fraction 1 was higher $(3.79 \mathrm{~g} / 100 \mathrm{~g})$ than the FAD of RBO $(2.53 \mathrm{~g} / 100 \mathrm{~g})$ (Figures 1 and 2).

\subsection{Squalene content}

Squalene is an essential intermediary for the biological synthesis of phytoterols. The primary commercial sources of squalene are shark and whale liver oil and other sources are olive oil, rice bran oil and wheat germ oil. Rice bran oil is a valuable source of squalene. The isolation of squalene from FAD of RBO depends on processing conditions and the results from the squalene estimation using an Agilent GC system revealed that the total Squalene content of the squalene-phytosterol (fraction 1) fraction was higher $(209.63 \mathrm{mg} / 100 \mathrm{~g})$ than the FAD of rice bran oil $(134 \mathrm{mg} / 100 \mathrm{~g})$ as shown in Table 4 and Figures 1 and 2.

\subsection{Fatty alcohol content}

Fatty alcohols are constituents of the unsaponifiable matter from rice bran oil, and are very important for utilization in various household products

TABLE 4. Composition ( $\% \mathrm{~W} / \mathrm{W})$ of the individual unsaponifiable matter components $(\gamma$ - oryzanol, total tocopherol, total phytosterol, squalene and fatty alcohol) in total unsaponifiable matter isolated from the FAD of rice bran oil, esterified fatty acid distillate and other fractions

\begin{tabular}{lccccc}
\hline Samples & $\begin{array}{c}\gamma-\text { Oryzanol } \\
(\mathbf{g m} / \mathbf{1 0 0 g m})\end{array}$ & $\begin{array}{c}\text { Total Tocopherol } \\
(\mathbf{m g} / \mathbf{1 0 0 g m})\end{array}$ & $\begin{array}{c}\text { Total Phytosterol } \\
(\mathbf{g m} / \mathbf{1 0 0 g m})\end{array}$ & $\begin{array}{c}\text { Squalene } \\
(\mathbf{m g} / \mathbf{1 0 0 g m})\end{array}$ & $\begin{array}{c}\text { Fatty alcohol } \\
(\mathbf{g m} / \mathbf{1 0 0 g m})\end{array}$ \\
\hline A & $0.38 \pm 0.03$ & $1.269 \pm 0.01$ & $2.53 \pm 0.01$ & $134 \pm 0.01$ & $8.16 \pm 0.01$ \\
B & $0.34 \pm 0.01$ & $0.224 \pm 0.01$ & $0.93 \pm 0.01$ & $69.49 \pm 0.01$ & $8.04 \pm 0.01$ \\
C & $0.33 \pm 0.01$ & $0.217 \pm 0.01$ & $1.26 \pm 0.01$ & $159.63 \pm 0.01$ & $61.60 \pm 0.01$ \\
D & $1.38 \pm 0.05$ & $2.10 \pm 0.01$ & - & - & - \\
E & $0.40 \pm 0.01$ & $0.35 \pm 0.01$ & $3.79 \pm 0.01$ & $209.63 \pm 0.01$ & $94.23 \pm 0.01$ \\
\hline
\end{tabular}

A=Fatty Acid Distillate (FAD) of Rice Bran Oil (RBO); B= Neutral glyceride of FAD from RBO;

$\mathrm{C}=95 \%$ alcohol treated Neutral glyceride; $\mathrm{D}=\gamma$-Oryzanol and Total tocopherol fraction;

$\mathrm{E}=$ Squalene and Phytosterol fraction. Each value is an average of three determinations, mean $\pm \mathrm{SD}$. 
and as surfactants. The total fatty alcohol content of the upper layer (hexane layer, fraction 1) fraction was higher $(94.23 \%)$ than the FAD of rice bran oil $(8.16 \%)$ (Table 4 and Figures 1 and 2$)$.

\section{CONCLUSIONS}

The present investigation leads to the development of a process technology for the isolation of the individual unsaponifiable matter components concentrate of $\gamma$-oryzanol and total tocopherols and as total phytosterols, squalene and fatty alcohol. The process involves autocatalytic chemical esterification with glycerol, solvent fractionation of the esterified product from 95\% ethanol; saponification of the alcohol extract and extraction with hexane for recovering the total phytosterols, squalene and fatty alcohol; and acidification of the alkaline phase followed by hexane extraction to recover tocopherols and $\gamma$-oryzanol. The recovery yield of the individual unsaponifiable matter constituents is almost quantitative.

\section{ACKNOWLEDGMENTS}

The authors acknowledge the School of Community Science and Technology, Indian Institute of Engineering Science and Technology, Shibpur, Howrah for providing the necessary facilities.

\section{REFERENCES}

Arab F, Alemzadeh I, Maghsoudi M. 2011. Determination of antioxidant component and activity of rice bran extract. Sci. Iran. 18, 1402-1406. https://doi.org/10.1016/J. SCIENT.2011.09.014

Bhattacharyya AC, Bhattacharyya DK. 1987. Deacidification of high FFA rice bran oil by reesterification and alkali neutralization. J. Am. Oil Chem. Soc. 64, 128-131. https://doi. org/10.1007/BF02546267

Bhilwade H Narayan et al. 2010. Squalene as Novel Food Factor. Current Pharm. Biotechnol. 11, 875-880. https://doi.org/ 10.2174/138920110793262088

Bhosle BM, Subramanian R. 2005. New approaches in deacidification of edible oils - a review. J. Food Eng. 69, 481-494. https://doi.org/10.1016/j.jfoodeng.2004.09.003

Chen MH, Bergman CJ. 2005. A rapid procedure for analysing rice bran tocopherol, tocotrienol and $\gamma$-oryzanol contents. J. Food Comp. Anal. 18, 139-151. https://doi.org/10.1016/j. jfca.2003.09.004

De BK, Bhattacharyya DK. 1999. Deacidification of high-acid rice bran oil by reesterification with monoglyceride. J. Am. Oil Chem. Soc. 76, 1243-1246. https://doi.org/10.1007/ s11746-999-0100-9

Delange DM et al. 2013. Determination of sterol and fatty alcohols in unsaponifiable matter of Roystonea regia fruits oil. J. Med. Plants Res. 7, 2736-2740.
Domínguez R et al. 2016. Effect of fat replacement by olive oil on the physico-chemical properties, fatty acids, cholesterol and tocopherol content of pâté'. Grasas Aceites 67, 133-141. https://doi.org/10.3989/gya.0629152

Escrich E, Solanas M, Moral R. 2014. Olive Oil and Other Dietary Lipids in Breast Cancer. Cancer Treat. Res. 7. 289-309. https://doi.org/10.1007/978-3-642-38007-5_17

Gomes TA et al. 2015. Effects of Tocols Rich Fraction Isolated from Rice Bran Oil Deodorizer Distillate on Plasma and Hepatic Lipid Concentrations in Rats. J. Biosci. Med. 3, 1-10. https://doi.org/10.4236/jbm.2015.39001

Gupta AK et al. 2011. Role of phytosterols in lipid-lowering: current perspectives. QJM 104, 301-308. https://doi.org/ 10.1093/qjmed/hcr007

Khatoon S, Gopalakrishna AG. 2004. Fat-soluble nutraceuticals and fatty acid composition of selected Indian rice varieties. J. Am. Oil Chem. Soc. 81, 939-943. https://doi.org/10.1007/ s11746-004-1005-5

Kombe GG et al. 2013. Pre-Treatment of High Free Fatty Acids Oils by Chemical Re-Esterification for Biodiesel Production-A Review. Advances Chem. Eng. Sci. 3, 242-247. https://doi.org/10.4236/aces.2013.34031

Lloyd BJ, Siebenmorgen TJ, Beers KW. 2000. Effects of Commercial Processing on Antioxidants in Rice Bran. Cereal Chem. J. Am. Assoc. Cereal Chem., Inc. 77, 551-555. https://doi.org/10.1094/CCHEM.2000.77.5.551

Malinowski JM, Gehret MM. 2010. Phytosterols for dyslipidemia. Am. J. Health-Sys. Pharm. 67, 1165-1173. https://doi. org/10.2146/ajhp090427

Nayik GA et al. 2015. Rice bran oil, the Future Edible Oil of India: A mini Review. J. Rice Res. 3, 1-8. https://doi.org/ 10.4172/2375-4338.1000151

Nijjar PS et al. 2010. Role of dietary supplements in lowering lowdensity lipoprotein cholesterol: A review. J. Clin. Lipidol. 4, 248-258. https://doi.org/10.1016/j.jacl.2010.07.001

Qu J et al. 2017. The effects of process technology on the physicochemical properties of peony seed oil. Grasas Aceites $\mathbf{6 8}$, 192-201. https://doi.org/10.3989/gya.1058162

Rani A et al. 2015. A rapid reversed-phase thin layer chromatographic protocol for detection of adulteration in ghee (clarified milk fat) with vegetable oils. J. Food Sci. Technol. 52, 2434-2439. https://doi.org/10.1007/s13197-013-1208-3

Smith TJ. 2000. Squalene: potential chemopreventive agent. Expert Opinion on Investigational Drugs, Taylor \& Francis. 9, 1841-1848. https://doi.org/10.1517/13543784.9.8.1841

Sohail M et al. 2017. Rice bran nutraceutics: A comprehensive review. Critical Reviews in Food Sci. Nut. 57, 3771-3780. https://doi.org/10.1080/10408398.2016.1164120

Troni KL et al. 2013. Study of Fatty Acid and Fatty Alcohol Formation from Hydrolysis of Rice Bran Wax. Chem. Eng. Transac. 32, 1747-1752. https://doi.org/10.3303/CET 1332292

Uluata S, Altuntaş Ü, Özçelik B. 2016. Biochemical Characterization of Arbequina Extra Virgin Olive Oil Produced in Turkey. J. Am. Oil Chem. Soc. 93, 617-626. https://doi.org/10.1007/s11746-016-2811-z

Wilson TA et al. 2007. Rice bran oil and oryzanol reduce plasma lipid and lipoprotein cholesterol concentrations and aortic cholesterol ester accumulation to a greater extent than ferulic acid in hypercholesterolemic hamsters. J. Nutrit. Biochem. 18, 105-112. https://doi.org/10.1016/j. jnutbio.2006.03.006

Yamamoto Y, Har S. 2012. Novel Fractionation Method for Squalene and Phytosterols Contained in the Deodorization Distillate of Rice Bran Oil. Scientific, Health and Social Aspects of the Food Industry. 1st edn. Japan: InTech, pp. 71-82. https://doi.org/10.5772/33126 